\title{
Os significados da corrida de rua para os frequentadores da represa municipal de São José do Rio Preto/SP
}

\author{
Leticia Masson* \\ Cinthia Lopes da Silva**
}

\begin{abstract}
Resumo
A corrida de rua pode ser analisada por diferentes pontos de vista. Neste estudo, a proposta foi de entender essa prática a partir de um referencial sociocultural. O objetivo foi analisar os significados da corrida de rua para os corredores da Represa Municipal da cidade de São José do Rio Preto/SP. Os significados têm fundamentação na ciência dos signos e são um meio para estudar todos os fenômenos culturais, pois apontam para um conjunto de mecanismos simbólicos que controlam o comportamento humano. Trata-se de pesquisa qualitativa e empírica. Foram utilizadas para a coleta de dados a observação participante, questionário sócio demográfico e entrevista semiestruturada. Os resultados mostraram que, para o grupo investigado, a corrida de rua não é mera mercadoria a ser consumida, mas uma prática que faz parte da vida dos corredores e envolve valores como o companheirismo, a construção de amizades, o estar junto com o outro e uma forma de compensação das tarefas do dia a dia.
\end{abstract}

Palavras-chave: Atividades de Lazer; Cultura; Corrida.

\section{Street race meanings for runners of São José do Rio Preto Municipal Park}

\begin{abstract}
Street race can be studied from different perspectives, and here we propose to understand this practice from a sociocultural viewpoint. Therefore, this study aims to analyze street race meanings for runners of São José do Rio Preto Municipal Park. The meanings are based on the science of signs and they are a way of studying all the cultural phenomena, since they point to a set of symbolic mechanisms which control human behavior. It is a qualitative research, of bibliographic and empirical type. For the investigated group, street race is not a mere product to be consumed, but it is a practice which is part of the runners lives, and there are values involved such as companionship, building of friendships and sharing of experiences which at the end become a kind of compensation for the daily routine. Keywords: Leisure Activities; Culture; Race.
\end{abstract}

* Mestre em Ciências do Movimento Humano pela UNIMEP e professora da Faculdade UNILAGO.

** Professora do PPG em Ciências do Movimento humano da UNIMEP 


\section{Introdução}

$\mathrm{Na}$ sociedade atual a corrida de rua tem demostrado ser um fenômeno sociocultural. Isso pode ser percebido por meio de um crescimento significativo do número de corredores e de eventos destinados à tal prática, envolvendo diferentes grupos sociais.

Para a identificação dos fatores que contribuem para o aumento do número de corredores na sociedade atual, partiu-se de um referencial em que é possível compreender a corrida de rua como uma das formas de manifestação cultural na sociedade contemporânea. A cultura é essencialmente semiótica e os significados têm fundamentação na ciência dos signos e são um meio para estudar todos os fenômenos culturais, pois apontam para um conjunto de mecanismos simbólicos que controlam o comportamento humano (Geertz, 1989).

A corrida de rua é uma atividade do contexto do lazer para as pessoas que correm com finalidade não profissional e pode ser associada a diferentes significados, tais como: recuperar as energias e reestabelecer a capacidade produtiva destinada a algumas obrigações como profissionais, sociais ou familiares; ser um meio de consumo de produtos e serviços (relógios com alta tecnologia, frequencímetros, roupas e tênis específicos para a prática da corrida de rua, além da contratação de serviços especializados como as assessorias esportivas e a participação em eventos), ser um meio para a manutenção da saúde, etc. Para além desses possíveis significados esta pesquisa tem como objetivo identificar e analisar os significados que os frequentadores da Represa Municipal de São José do Rio Preto atribuem à corrida de rua.

\section{Material e método}

Este trabalho trata-se de um estudo qualitativo. Segundo Minayo (2001), há uma relação entre o real e o sujeito, que não pode ser traduzido através de números, pois está intimamente relacionada a subjetividade do sujeito e o mundo objetivo. Este tipo de estudo qualitativo envolve um universo de significados, crenças, valores e atitudes. Foi realizada pesquisa de campo, que teve como finalidade investigar os significados atribuídos à corrida de rua pelos frequentadores da Represa Municipal de São José do Rio Preto/SP.

A escolha pela represa, deve-se ao fato de ser um dos principais espaços públicos de lazer da cidade de São José do Rio Preto. A Represa Municipal de São José do Rio Preto é composta pelo lago I, lago II e lago III, além de ser uma área de extrema beleza natural e considerada o cartão postal da cidade. De acordo com Portal Rio Preto
(2015), atualmente há aproximadamente 25 mil corredores amadores que frequentam a Represa Municipal de São José do Rio Preto. Na pesquisa de campo foi realizada em dois períodos: o período matutino das $06 \mathrm{~h}$ às $10 \mathrm{~h} \mathrm{e}$ o período noturno das $18 \mathrm{~h}$ às $20 \mathrm{~h}$ devido ao maior fluxo de corredores nesses horários. Foram entrevistados os corredores que frequentavam a Represa Municipal de São José do Rio Preto, os lagos II e III.

Outro critério adotado para a seleção dos participantes é que fossem adultos, homens e mulheres, frequentadores semanais da represa, com faixa etária superior a dezoito anos. A escolha pelo lago II e lago III se deu devido ao maior número de corredores presentes nesses lagos. A escolha por essa faixa etária deve-se ao fato de serem pessoas que podem apresentar diferentes interesses relacionados à corrida de rua. A amostra de 40 pessoas foi estipulada pela saturação de dados (Duarte, 2000)

Foi utilizado nesta pesquisa os princípios da etnografia para a investigação dos corredores de rua, frequentadores da represa de São José do Rio Preto. Segundo Geertz (1989), praticar a etnografia é não se limitar apenas em escrever diários ou mapear o campo de pesquisa, mas sim, realizar uma descrição densa em relação ao que o grupo de pessoas faz e os significados desses atos para elas, não deixando de relacionar o contexto em que essas pessoas vivem. Utilizamos como técnicas de pesquisa a observação participante, questionário e entrevista semiestruturada. A observação participante, de acordo com Bruyne, Herman \& Schoutheete (1982), pressupõe a observação direta e convívio com o grupo. A partir dessa técnica foi possível o acesso a dados que complementaram as entrevistas. Foi observado durante as corridas se os corredores corriam sozinhos ou acompanhados por assessoria esportiva ou por outro corredor; como era a vestimenta e uso de acessórios esportivos e a frequência do corredor na represa. Após observação foram abordados os corredores para apresentação do estudo e identificar qual prática ele realiza na represa, qual a frequência e se ele contratou algum tipo de serviço especializado.

A partir destes dados foram selecionamos pessoas que praticam a corrida de rua com regularidade. Para identificarmos os significados da corrida de rua para os corredores da Represa Municipal de São José do Rio Preto, utilizamos as entrevistas semiestruturadas, procedimento considerado por Triviños (1987) como um dos principais meios na pesquisa qualitativa em Ciências Humanas. Tais entrevistas foram baseadas em um roteiro, permitindo ao entrevistado seguir espontaneamente a 
linha de seu pensamento e de suas experiências. A pergunta central na entrevista foi: Quais os significados da corrida de rua para você?

Ao término das entrevistas e das observações participantes foi realizada a terceira fase da pesquisa, referente à análise dos dados coletados na pesquisa de campo. Para isso tivemos como base os princípios da pesquisa etnográfica com descrição densa, que possui quatro características:

Ela é interpretativa; o que ela interpreta é o fluxo do discurso social e a interpretação envolvida consiste em tentar salvar o "dito" num tal discurso da sua possibilidade de extinguir-se e fixá-lo em formas pesquisáveis. Há ainda, em adiantamento, uma quarta característica de tal descrição, pelo menos como eu a pratico: ela é microscópica (Geertz 1989, p.31).

Diante dessa perspectiva, a finalidade da terceira fase da pesquisa foi interpretar os discursos dos corredores da Represa Municipal de São José do Rio Preto. Portanto, tivemos como procedimento a análise do comportamento social em relação aos significados que os sujeitos pesquisados atribuem à corrida de rua. A descrição da análise dos dados se constituiu como uma teia de significados, levando-nos às singularidades de cada corredor e ao coletivo, de modo a considerar o que a maioria respondeu em relação aos significados para os corredores de rua da Represa Municipal de São José do Rio Preto. Para dar suporte à interpretação dos significados foi utilizada a pesquisa bibliográfica realizada na primeira fase da investigação e as entrevistas foram gravadas. Os indivíduos entrevistados apresentaram idade mínima de 18 anos de idade e máxima de 67 anos de idade. A pesquisa foi aprovada pelo Comitê de Ética da Universidade Metodista de Piracicaba, sob protocolo no 138/2015. (Veja Quadro 1).

\section{A Represa Municipal de São José do Rio Preto e as observações da pesquisa}

A Represa Municipal de São José do Rio Preto foi fundada em 1956. De acordo com o Portal Rio Preto (2015), entre 1987 e 1990 os arquitetos Jamil Kfouri e Myrthes Baffi executaram o projeto "Plano de área verde". Em 1988, a represa recebeu significativa revitalização e um novo paisagismo. O espaço da represa é composto por três lagos: Lago I, Lago II e Lago III. O Lago I possui pista de caminhada no entorno de suas margens, fonte luminosa musical que possui mais de 30 jatos de água com alcance de aproximadamente 15 metros de altura e tem em sua extensão o Anfiteatro Nelson Castro.

O Lago II, possui pista de caminhada com 2.700 metros de extensão, dois sanitários públicos, sendo um masculino e outro feminino, 22 quiosques que formam a praça de alimentação, uma ilha no centro do lago habitada por diversas aves e animais silvestres, 19 quiosques para eventuais churrascos, playground, três academias ao ar livre, três academias ecológicas, paisagismo e arborização em toda extensão da pista de caminhada, bancos e mesas no seu entorno, jardim japonês, quadra de areia, exposição de um avião Impala AT-26A doado Força Aérea Brasileira - FAB, passarela sobre o lago que permite uma visão ampla de suas margens e da ilha.

O Lago III está localizado em frente aos condomínios de luxo, possui pista de caminhada e ciclovia ambas com 2.900 metros de extensão com asfalto colorido e demarcado, 3 conjuntos de equipamentos de ginástica para alongamento e musculação, sanitários públicos masculino e feminino, bebedouros refrigerados e guarda municipal para dar apoio aos usuários. A Represa Municipal de São José do Rio Preto/SP é um local muito atrativo e agradável para a prática da corrida de rua, isso foi revelado no depoimento dos participantes da pesquisa. Pode-se notar no conjunto das falas dos entrevistados que estar no meio natural, ao ar livre, entre as árvores e os lagos, exerce grande influência na ida até o local.

\section{Resultados e Discussão}

A partir da técnica de observação participante e das entrevistas pode-se acompanhar os dias de práticas da corrida, assim como os eventos relacionados à corrida de rua. Observou-se que os corredores apresentavam dois diferentes comportamentos, um grupo realizava uma prática mais intensa e outro praticava a corrida de forma despreocupada e ao término da corrida todos se reuniam formando uma roda de amigos. Foi possível observar o potencial da corrida de rua como uma atividade que é compartilhada entre os indivíduos e identificar alguns valores compartilhados, tais como: amizade, companheirismo e solidariedade.

Notou-se que alguns sujeitos faziam uso de camisetas das assessorias esportivas, meias de compressão e tênis das mais variadas marcas. A relação com o consumo de produtos específicos e a corrida guiada por assessorias esportivas foi possível identificar nos sujeitos que frequentavam o lago III da Represa Municipal de São José do Rio Preto/SP. Toda a extensão do lago III é preenchida por assessorias esportivas. Foi possível compreender que o consumo de produtos, observado pelas 
Quadro 1 - Especificações dos entrevistados quanto ao gênero, profissão, idade, qual lago frequenta e assessoria esportiva.

\begin{tabular}{|c|c|c|c|c|c|}
\hline ENTREVISTADO & GÊENRO & PROFISSÃO & IDADE & LAGO & ASSESSORIA \\
\hline 1 & Masculino & $\begin{array}{c}\text { Profissional de Educação } \\
\text { Física }\end{array}$ & 25 & III & Não \\
\hline 2 & Feminino & Professora & 57 & III - II & $\operatorname{Sim}$ \\
\hline 3 & Masculino & Func. Público & 35 & III - II & $\operatorname{Sim}$ \\
\hline 4 & Masculino & Empresário & 38 & III & Não \\
\hline 5 & Feminino & Cabeleireira & 34 & III & Não \\
\hline 6 & Masculino & Policial Militar & 33 & III & $\operatorname{Sim}$ \\
\hline 7 & Masculino & Policial Militar & 38 & III & $\operatorname{Sim}$ \\
\hline 8 & Masculino & Empresário & 32 & III & Não \\
\hline 9 & Masculino & Engenheiro & 31 & III & Não \\
\hline 10 & Masculino & Estudante & 18 & III & Não \\
\hline 11 & Masculino & Estudante & 25 & III & Não \\
\hline 12 & Masculino & Administrador & 38 & III & Não \\
\hline 13 & Masculino & Administrador & 39 & III & Não \\
\hline 14 & Masculino & Dentista & 34 & III & Não \\
\hline 15 & Masculino & Moto Boy & 48 & III & $\operatorname{Sim}$ \\
\hline 16 & Masculino & Soldador & 26 & III & $\operatorname{Sim}$ \\
\hline 17 & Masculino & $\begin{array}{c}\text { Profissional de Educação } \\
\text { Física }\end{array}$ & 49 & III & $\operatorname{Sim}$ \\
\hline 18 & Masculino & Advogado & 67 & $\mathrm{III}-\mathrm{II}$ & $\operatorname{Sim}$ \\
\hline 19 & Masculino & Advogado & 45 & III & $\operatorname{Sim}$ \\
\hline 20 & Feminino & Professora & 49 & III & $\operatorname{Sim}$ \\
\hline 21 & Masculino & Projetista & 33 & II & Não \\
\hline 22 & Masculino & Jogador de Futebol & 18 & II & Não \\
\hline 23 & Masculino & Engenheiro & 23 & $\mathrm{II}-\mathrm{III}$ & Não \\
\hline 24 & Feminino & Empresária & 38 & II & $\operatorname{Sim}$ \\
\hline 25 & Feminino & Professora & 54 & II & Não \\
\hline 26 & Feminino & $\begin{array}{c}\text { Profissional de Educação } \\
\text { Física }\end{array}$ & 34 & II & Não \\
\hline 27 & Masculino & Aposentado & 66 & $\mathrm{II}-\mathrm{III}$ & Não \\
\hline 28 & Feminino & Enfermeira & 31 & II & Não \\
\hline 29 & Feminino & Advogada & 38 & II & $\operatorname{Sim}$ \\
\hline 30 & Feminino & Estudante & 20 & II & Não \\
\hline 31 & Masculino & Jornalista & 42 & II & Não \\
\hline 32 & Masculino & Mestre de Obras & 47 & II & Não \\
\hline 33 & Masculino & Empresário & 50 & II & Não \\
\hline 34 & Masculino & Vendedor & 32 & II & Não \\
\hline 35 & Masculino & Médico & 46 & II & Não \\
\hline 36 & Masculino & Professor & 38 & II & Não \\
\hline 37 & Masculino & Servente de obras & 29 & II & Não \\
\hline 38 & Masculino & Professor & 42 & II & Não \\
\hline 39 & Masculino & Engenheiro & 39 & II & Não \\
\hline 40 & Masculino & Taxista & 54 & II & Não \\
\hline
\end{tabular}




\section{OS SIGNIFICADOS DA CORRIDA DE RUA PARA OS FREQUENTADORES DA REPRESA \\ MUNICIPAL DE SÃO JOSÉ DO RIO PRETO/SP}

roupas e acessórios próprios da corrida de rua, pelos corredores os identifica em um tipo de grupo caracterizado alto nível socioeconômico. Uma pesquisa realizada com as Tribos Urbanas mostra o fenômeno dos sujeitos se agruparem, pertencerem a um grupo e criarem uma identidade (Magnani, 1992). Dentre as atividades realizadas na Represa Municipal de São José do Rio Preto/SP a pista de caminhada/corrida é o local onde predomina o maior fluxo dos frequentadores.

Ao analisar a corrida de rua na Represa Municipal de São José do Rio Preto faz-se necessário contemplar a questão do "espaço e manchas" como algo essencialmente expressivo por meio de um conjunto de representações, definido como:

Pedaço designando um espaço intermediário entre o privado e o público, onde se desenvolve a sociabilidade básica, mais ampla, densa, significativa e estável que as relações formais e individualizadas impostas pela sociedade; as manchas, áreas contíguas do espaço urbano permeadas por equipamentos e espaços que marcam seus limites e viabilizam uma atividade ou prática predominante. (Magnani \& Souza, 2007, p. 320).

No caso do local investigado identificou-se um equipamento que pode ser considerado o pedaço para seus corredores que se estende a mancha, já que eles se concentram nesse local para a prática da corrida e essa área é parte de uma área mais ampliada e contígua do espaço urbano.

Ao reportar-se à corrida de rua não estamos apenas descrevendo uma atividade física pela perspectiva de uma atividade que envolve gasto de energia, mas sim ampliando o conhecimento sobre esta prática corporal, entendendo-a como uma prática social, cultural e histórica e os significados que os sujeitos atribuem a ela, que se dá a partir de uma certa relação com o espaço e contexto social em que vivem.

Com relação a pergunta central desta pesquisa "quais os significados da corrida de rua para você?" os entrevistados demonstraram certo posicionamento diante das referências que circulam em nosso meio sobre valores, crenças, atitudes, motivos e aspirações. A partir da análise de dados, a maioria dos entrevistados revelaram como principais significados da corrida de rua o fato de ela ser um meio de sociabilidade e de compensação às tarefas do dia-a-dia.
"A corrida foi assim, eu sempre gostei muito de fazer exercícios, embora eu não tenha um corpo atlético, pois sou um pouco sedentária. Mas ela é assim, uma atividade que me desestressa, pra mim que sou uma profissional que trabalha o tempo todo com problemas, me ajuda a desestressar. A corrida tem esse papel na minha vida, de fazer com que de vez em quando eu esteja entre amigos. Eu foco mais nisso, estar entre amigos, do que só praticar o exercício" (Entrevistada 29).

"É quase uma religião eu costumo dizer. É onde eu medito, eu estou correndo e estou colocando meus pensamentos em ordem, estou me organizando, pensando no meu trabalho, como que eu vou fazer. Além disso, estou sempre revendo os amigos, me divirto com essa situação e acabo descansando de um dia pesado" (Entrevistado 31).

Este cenário apresentado pelos participantes mostra certa correspondência aos três Ds do lazer Dumazedianos, que significa: descanso, divertimento e desenvolvimento. Essas categorias apontadas pelos entrevistados mostram o caráter compensatório da corrida de rua, mas também outro sentido, diferente do proposto por Dumazedier (1980): a valorização do outro, da amizade, do companheirismo. Assim, pudemos notar que os entrevistados transitam entre as duas formas - de construção de novos valores que tem como base a sociabilidade, o estar junto com o outro, a construção de amizades e o sentido de compensação às obrigações sociais.

Vale salientar a relação existente entre o interesse dos entrevistados na corrida de rua e na construção de amizades e de estar com outras pessoas. Isso se dá por meio dos eventos - provas de ruas realizadas, pelo espaço público em comum e pela interação entre as pessoas, que pode ser observado nas respostas de alguns entrevistados.

\footnotetext{
"Não gosto de correr sozinho, o percurso fica maior quando estou só, o único lado ruim é que quando um não vai, o outro também não" (Entrevistado 07).

"Na verdade, eu sempre gostei muito de esporte e estar ali no evento me traz uma ansiedade boa, uma vontade de vencer, de estar entre outros corredores e a sensação de estar competindo, na maioria das vezes com meu próprio tempo, é maravilhosa" (Entrevistado 13).
} 
"Participar de eventos com meus amigos é o que me estimula para continuar correndo. Eu gosto de competir com eles" (Entrevistado 17).

Romanini (2009) afirma que a possibilidade de relacionar o exercício físico à ampliação do círculo de amizades ajuda a explicar o grande número de adeptos aos grupos de corrida de rua na contemporaneidade. Todas essas respostas trouxeram dados para traçar um quadro sobre o interesse social do lazer. Nota-se que o convívio com diferentes grupos e a troca de experiências são evidentes em relação aos significados atribuídos à corrida de rua.

Nota-se a relevância atribuída pelos corredores ao convívio com o outro e a construção de amizades, pode-se identificar contribuições para o desenvolvimento pessoal e social dos corredores (no sentido do desenvolvimento humano e de transformação social). A diversidade que se concretiza em diferentes condições sociais (classes sociais), culturais (etnias e valores), de gênero, regionais, dentre outras, se torna visível tanto nos grupos de corrida presentes na Represa Municipal de São José do Rio Preto/SP, como nos corredores que correm sozinhos, pois apesar de correrem só, eles acabam conhecendo outros corredores que praticam a corrida. Além do mais, grupos de classe média ou de outras classes populares compartilham do mesmo espaço físico, mesmo tendo diferentes realidades sociais. Nesse sentido, pode-se considerar que a corrida de rua é uma prática que favorece a relação entre os diferentes sujeitos. Diante desses apontamentos, se torna fundamental entender, o que leva as pessoas a aderirem a essa prática.

"Me interessei a princípio pela corrida por não conseguir caminhar mais de 200 metros sem me cansar, como eu era fumante, decidi trocar o cigarro pela corrida, pra mim a escolha foi superação" (Entrevistado 14).

"No meu caso eu optei por praticar a corrida de rua para poder emagrecer, pois todos falavam o quanto era rápido o resultado, então eu quis traçar um objetivo de perda de peso e superar meus limites" (Entrevistado 30).

"Ah, a corrida de rua é um esporte mais barato, você tem que ter apenas um tênis, colocar uma bermuda, uma roupa leve. Escolhi a corrida de rua por não ser um esporte tão caro" (Entrevistado 37).
As duas primeiras falas em destaque revelam que $o$ interesse inicial dos sujeitos na corrida foi para a obtenção de melhorias para a saúde, a perda de peso, o bem para o corpo, o que reporta ao discurso amplamente difundido em nosso meio social de que a prática de esportes faz bem à saúde. Assim, as pessoas indicam que começaram a correr instigadas por esse discurso. Para além do mero discurso sobre a associação da prática de esportes e a saúde, há dados científicos que comprovam os benefícios para a saúde (vista do ponto de vista biológico) de práticas como a corrida. No entanto, pensar a questão saúde é algo complexo, dado que vários fatores devem ser considerados para se discutir a saúde como: os direitos sociais, a possibilidade de os sujeitos fazerem opções na vida, terem condições dignas de vida, etc. (Carvalho, 2001). Como define a Organização Mundial da Saúde - OMS (2014) "um estado de completo bem-estar físico, mental e social e não somente ausência de afecções e enfermidades". Esse é o conceito mais aceito no campo da saúde, no entanto, Carvalho (2001) apresenta outros elementos que são determinantes para a pessoa ter saúde, que não são contemplados nesse conceito da OMS, assim apresentamos os dois conceitos que podem ser aqui entendidos de forma complementar. Assim, a corrida pode trazer benefícios fisiológicos para os sujeitos, mas pensar a questão saúde requer pensar em outros aspectos para além da saúde física.

A última fala em destaque do entrevistado 37 nos revelou que a corrida é um esporte de baixo custo, que mesmo as pessoas que não têm uma classe econômica alta podem vivenciá-la. De acordo com Vanucci (2012), a corrida de rua vem se apresentando como uma modalidade popular, por ser uma prática democrática, de baixo custo e de fácil adaptação.

As respostas acima indicam quais os elementos foram predominantes para que os corredores iniciassem na corrida de rua e como ao logo do tempo de prática novos significados foram tecidos como a questão da sociabilidade. De acordo com Lopes, Velozo e Rodrigues Jr. (2008, p. 47) para que seja possível a compreensão dos significados das ações humanas se faz necessário "identificar as intenções, as emoções, as expressões que os diferentes sujeitos realizam, a posição ocupada por eles no contexto em que vivem, suas condições e história de vida”. Os autores evidenciam a relevância de reconhecer a si próprio como sujeito e, simultaneamente como outro.

Diante dessa linha de pensamento pode-se ressaltar, que: 
Tornar-se humano é tornar-se individual, e nós nos tornarmos individuais sob a direção dos padrões culturais, sistemas de significados criados historicamente em termos dos quais damos forma, ordem, objetivo e direção às nossas vidas. (Geertz, 1989, p. 64).

É a partir dessa forma de pensar que não podemos fragmentar o ser humano, dividindo-o em biológico e cultural, mas sim pensarmos que o ser humano se constitui por múltiplos fatores que se completam (biológico, cultural, social, psicológico), assim como pode-se notar pelos próprios conceitos de saúde aqui apresentados de Carvalho (2001) e da OMS. Assim, consideramos a cultura de forma dinâmica, uma atividade humana que gera contínua produção de significados na vida social. Nossa análise se centrou nos significados da corrida de rua para frequentadores da Represa Municipal de São José do Rio Preto/SP.

\section{Considerações finais}

Este estudo teve como principal objetivo identificar e analisar os significados da corrida de rua para os frequentadores da Represa Municipal de São José do Rio Preto/SP. A pesquisa corroborou a evidência de que a represa é um espaço de lazer que possibilita a interação e a sociabilidade entre os sujeitos, pela prática regular da corrida de rua, pelas conversas em grupos de corridas e pela participação dos sujeitos em eventos.

A corrida é um fenômeno sociocultural na contemporaneidade que está em destaque por ser praticada, assistida e discutida em diferentes segmentos. É realizada por corredores que correm sozinhos ou em grupos, como forma de competição com seus próprios pares ou consigo mesmo. Destaca-se a corrida de rua como cultura vivenciada no tempo disponível dos corredores. Ao analisar as respostas dos entrevistados ficou evidente seus interesses na corrida de rua pelo aspecto social e pela forma de compensação às tarefas do dia-a-dia.

Nas observações, pode-se notar a interação dos sujeitos em diferentes níveis sociais, gêneros e faixa etária e como a corrida de rua reúne muitos corredores em eventos, sendo necessário para a realização desses eventos o uso de espaços públicos, como as ruas urbanas.

Com relação ao consumo de acessórios esportivos usados pelos corredores e a contratação de assessorias esportivas, notou-se que, por mais que há corredores que fazem o consumo desses assessórios e estão inscritos em assessorias esportivas, os valores relacionados à corrida de rua ultrapassam o consumo desses produtos. A corrida de rua para os corredores da Represa Municipal de São José do Rio Preto não é mera mercadoria a ser consumida, mas sim, uma prática que faz parte da vida dos corredores, que envolve valores como o companheirismo, a construção de amizades, o estar junto com o outro. É interessante notar nesta pesquisa a forma como os corredores se vestem. Não há uma obrigação da apropriação de camisetas específicas de corrida, mas usar a camiseta que evidencia a participação em eventos e pertencimento a um grupo faz toda a diferença para esses corredores.

Esta pesquisa contribui com o campo da Educação Física e do lazer por trazer uma discussão e investigação sobre a corrida de rua a partir de um olhar para a dinâmica cultural em que os corredores da Represa Municipal de São José do Rio Preto estão inseridos, demonstrando que existe a atribuição de valores e significados à corrida de rua por seus praticantes. Essa produção de valores e significados identificados levam os sujeitos ao desenvolvimento pessoal e social, pelo convívio com outros corredores, pela troca de experiências, pelo companheirismo e pela amizade, tais significados também revelam a função compensatória da corrida de rua para os entrevistados, para que consigam lidar melhor com as atividades do cotidiano. Estudos futuros poderão ser desenvolvidos no sentido de adentrar a questão da sociabilidade, de modo a verificar como se dá a interação entre os sujeitos a partir da prática da corrida de rua.

\section{Agradecimentos}

Agradecemos à Capes pela bolsa para realização da pesquisa.

\section{Referências}

Bruyne, P., Herman, J., \& Marc. (1982). Dinâmica da pesquisa em ciências sociais. 3 ed. Rio de Janeiro: Francisco Alves.

Carvalho, Y. M. (2001). Atividade física e saúde: onde está e quem é o "sujeito" da relação? Rev. Bras. Cienc. Esporte, 22 (2), 9-21.

Duarte, J. J. F. (2000). O sentido dos sentidos: a educação (do) sensível. Tese de Doutorado. Faculdade de Educação da Unicamp.

Dumazedier, J. (1980). Valores e conteúdos culturais do laz̧er. São Paulo: Sesc.

Geertz, C. (1989) A interpretação das culturas. Rio de Janeiro: Livros Técnicos e Científicos (LTC).

Lopes, S., Velozo, C. E. Luis \& Rodrigues Jr, J. C. (2008). Pesquisa qualitativa em educação física: possibilidades de construção de conhecimento a partir do referencial cultural. Belo Horizonte, Educação em Revista, 48, 37-60

Magnani, J. G. C. (1992). “Tribos urbanas: metáfora ou categoria?”. Cadernos de Campo.

Magnani, J. G. C. \& Souza, B.M. (2007). Jovens na Metrópole: etnografias de circuitos de lazer, encontro e sociabilidade. Cadernos de Campo, São Paulo, n.18, p. 1-354, 2009. Ed. Terceiro Nome.

Minayo, M. C. (2001) Ciência, técnica e arte: o desafio da Pesquisa Social. In: Maria Cecilia Minayo (Org.), Pesquisa social: teoria, método e criatividade ( $p$ p. 09-30). Petrópolis: Vozes. 
Organização Mundial da Saúde - OMS (2014) http://sinus.org.br/2014/ wp-content/uploads/2013/11/OMS-Guia-Online.pdf. Acesso em 05 de maio de 2018.

Portal Rio Preto. Represa Municipal. Disponível em: http://www.riopreto.sp.gov. br/PortalGOV/do/subportais_Show?c=225. Acesso em: 23 dezembro, 2015.

Triviños, A. (1987). Introdução a pesquisa qualitativa em ciências sociais: a pesquisa qualitativa em educação. 1ed. São Paulo: Atlas.
Romanini, C. (2009). Correr é fazer amigos. Rio de Janeiro: Zahar.

Vanucci, L. H. T. (2012). Corrida de rua, cada vez mais nos pés do povo. A folha de São Paulo. 2012 nov. Disponível em: http://www.portaleducacao.com.br/ educacaofisica/artigos/20880/corrida-de-rua-cada-vez-mais-nos-pes-do-povo. Acesso em: 10 de set. 2014.

Submetido em: 27-7-2017

Aceito em: 8-7-2018 